\title{
ANNUAL CONFERENCE 2015
}

\section{How should we measure online learning activity?}

\author{
Tim O’Riordan ${ }^{\mathrm{a} *}$, David E. Millard ${ }^{\mathrm{a}}$ and John Schulz ${ }^{\mathrm{b}}$ \\ ${ }^{a}$ School of Electronics and Computer Science, University of Southampton, Southampton, UK; \\ ${ }^{b}$ Southampton Education School, University of Southampton, Southampton, UK \\ (Received 20 October 2015; final version received 8 March 2016)
}

\begin{abstract}
The proliferation of Web-based learning objects makes finding and evaluating resources a considerable hurdle for learners to overcome. While established learning analytics methods provide feedback that can aid learner evaluation of learning resources, the adequacy and reliability of these methods is questioned. Because engagement with online learning is different from other Web activity, it is important to establish pedagogically relevant measures that can aid the development of distinct, automated analysis systems. Content analysis is often used to examine online discussion in educational settings, but these instruments are rarely compared with each other which leads to uncertainty regarding their validity and reliability. In this study, participation in Massive Open Online Course (MOOC) comment forums was evaluated using four different analytical approaches: the Digital Artefacts for Learning Engagement (DiAL-e) framework, Bloom's Taxonomy, Structure of Observed Learning Outcomes (SOLO) and Community of Inquiry (CoI). Results from this study indicate that different approaches to measuring cognitive activity are closely correlated and are distinct from typical interaction measures. This suggests that computational approaches to pedagogical analysis may provide useful insights into learning processes.
\end{abstract}

Keywords: CMC; CSCL; content analysis; learning analytics; MOOCs; pedagogical frameworks

\section{Introduction}

The usefulness of computer-mediated communication (CMC) in supporting teaching and learning, by increasing exposure to new ideas and building social capital through informal networks has been recognised for some time (Hiltz 1981; Kovanovic et al. 2014), as has the distinctive nature of discourse in these settings (Cooper and Selfe 1990; Leshed et al. 2007). The automatic creation of transcripts of interactions, made possible by $\mathrm{CMC}$ technology, provides a unique and powerful tool for analysis especially with the large datasets offered by Massive Open Online Courses (MOOCs). However, while the content of CMC continues to be viewed as a 'gold mine of information concerning the psycho-social dynamics at work among students, the learning strategies adopted, and the acquisition of knowledge and skills' (Henri 1992, p. 118), the reliability of analysis and evaluation measures is questioned (De Wever et al. 2006).

This study builds on earlier learning analytics work comparing pedagogical coding of comments associated with Web-based learning objects with typical

\footnotetext{
*Email: tor1w07@soton.ac.uk

Responsible Editor: Carlo Perrotta, University of Leeds, United Kingdom.
}

Research in Learning Technology 2016. (C) 2016 T. O'Riordan et al. Research in Learning Technology is the journal of the Association for Learning Technology (ALT), a UK-based professional and scholarly society and membership organisation. ALT is registered charity number 1063519. http://www.alt.ac.uk/. This is an Open Access article distributed under the terms of the Creative Commons Attribution 4.0 International License (http://creativecommons.org/licenses/by/4.0/), allowing third parties to copy and redistribute the material in any medium or format and to remix, transform, and build upon the material for any purpose, even commercially, provided the original work is properly cited and states its license. 


\section{T. O'Riordan et al.}

interaction measures adopted by learning analytics research. These typical measures include intentional rating systems (e.g. 'like' buttons) (Ferguson and Sharples 2014), 'opinion mining' techniques (e.g. sentiment analysis) (Ramesh et al. 2013), and assessments of language complexity (e.g. words per sentence) (Walther 2007). 'Likes' are a commonly used rating mechanism that are adopted to measure personal attitudes (Kosinski, Stillwell, and Graepel 2013); sentiment analysis has been used in social media research to explore people's mood and attitudes towards politics, business and a number of different variables, including evaluating satisfaction with online courses (Wen, Yang, and Rosé 2014); and the number of words per sentence has been identified as a signifier of language complexity in a number of studies (Khawaja et al. 2009; McLaughlin 1974; Robinson, Navea, and Ickes 2013).

In this study, we seek to explore the potential of content analysis (CA) methods that are founded on pedagogical theory, to test correlations - with each other and with typical interaction measures - with the aim of enhancing standard approaches to learning analytics. Specifically, we set out to test the hypotheses that CA methods, while ostensibly measuring different aspects of learning interactions, are closely associated, and that ratings derived from these methods are also correlated with the typical interaction measures discussed earlier. Potential correlations between these measurements have important implications for the development of automated analysis of online learning.

\section{Related work}

In recent years, computer-supported collaborative learning (CSCL) research has witnessed a change in learning design focus, from instructor-led to learner-centred approaches. Concurrent with this, there have been significant developments in CA to understand CSCL. Naccarato and Neuendorf (1998) describe CA as the 'systematic, objective, quantitative analysis of message characteristics' (p. 20). However, the importance of evaluating from a qualitative perspective was acknowledged nearly 20 years earlier in Hiltz's (1981) seminal paper on CMC, where combined qualitative and quantitative approaches are recommended to build a better picture. In addition, Gerbic and Stacey (2005) note that researchers tend to present qualitatively analysed units of meaning within discussions as numeric data in order to apply statistical analysis. This is similar to the method adopted in the present study, where comments have been evaluated in the context of different pedagogical coding models, rated appropriately, and analysed with statistical tools.

Weltzer-Ward's (2011) investigation of 56 CA methods used in studies of online asynchronous discussion identified Community of Inquiry (CoI) (Garrison, Anderson, and Archer 2010), and analyses adopting Bloom's Taxonomy (Bloom et al. 1956) and the Structure of Observed Learning Outcomes (SOLO) (Biggs and Collis 1982) as widely used methods with high citation counts, accounting for nearly $65 \%$ of the papers reviewed. In addition to these instruments, a novel CA method developed from the Digital Artefacts for Learning Engagement (DiAL-e) (Atkinson 2009) is employed in this study.

\section{Bloom's Taxonomy of the cognitive domain}

'Bloom's Taxonomy' (Bloom et al. 1956) has become a popular and well-respected aid to curriculum development and means of classifying degrees of learning. 
As amended by Krathwohl (2002), Bloom consists of a hierarchy that maps learning to six categories of knowledge acquisition (Table 1) each indicating the achievement of understanding that is deeper than the preceding category. In CA studies, Yang et al. (2011) aligns Bloom with Henri (1992), a precursor of CoI. In addition, Kember's (1999) association of Bloom's dimensions with Mezirow's (1991) 'thoughtful action' category (e.g. writing), and the utility of mapping word types to Bloom's levels of cognition (Gibson, Kitto, and Willis 2014) are supportive of the use of the Taxonomy in this study.

\section{Structure of Observed Learning Outcome taxonomy}

Similar to Bloom, SOLO (Biggs and Collis 1982) is a hierarchical classification system that describes levels of complexity in a learner's knowledge acquisition as evidenced in their responses (including writing). SOLO adopts five categories (Table 2) to distinguish levels of comprehension. SOLO-based studies include Gibson, Kitto, and Willis (2014) who map the taxonomy to their proposed learning analytics system, and Karaksha et al. (2014) use Bloom and SOLO to evaluate the impact of e-learning tools in a higher education setting. In addition, Shea et al. (2011) adopt CoI and SOLO to evaluate discussion within online courses, and Campbell (2015) and Ginat and Menashe (2015) apply SOLO to the assessment of writing.

\section{Community of Inquiry}

The structure of CoI is based on the interaction of cognitive presence, social presence and teaching presence, through which knowledge acquisition takes place within learning communities (Garrison, Anderson, and Archer 2001). As the current study is concerned with identifying evidence of critical thinking associated with learning objects, the focus is on the categorisation of the cognitive presence dimension which attends to the processes of higher-order thinking within four types of dialogue (Table 3) - starting with a initiating event and concluding with statements that resolve the issues under discussion.

Dringus (2012) suggests that the CoI provides 'an array of meaningful and measurable qualities of productive learning and communication...' (p. 96).

Table 1. Bloom's Taxonomy.

\begin{tabular}{|c|c|}
\hline Bloom score & Descriptor \\
\hline 0 - Off-topic & $\begin{array}{l}\text { There is written content, but not relevant to the subject under } \\
\text { discussion. }\end{array}$ \\
\hline 1 - Remember & $\begin{array}{l}\text { Recall of specific learned content, including facts, methods, and } \\
\text { theories. }\end{array}$ \\
\hline 2 - Understand & $\begin{array}{l}\text { Perception of meaning and being able to make use of knowledge, } \\
\text { without understanding full implications. }\end{array}$ \\
\hline 3 - Apply & Tangible application of learned material in new settings. \\
\hline 4 - Analyse & $\begin{array}{l}\text { Deconstruct learned content into its constituent elements in order } \\
\text { to clarify concepts and relationships between ideas. }\end{array}$ \\
\hline 5 - Evaluate & Assess the significance of material and value in specific settings. \\
\hline $6-$ Create & $\begin{array}{l}\text { Judge the usefulness of different parts of content, and producing a } \\
\text { new arrangement. }\end{array}$ \\
\hline
\end{tabular}

Source: Bloom et al. 1956; Chan et al. 2002; Krathwohl 2002. 
Table 2. SOLO taxonomy.

\begin{tabular}{|c|c|}
\hline SOLO score & Descriptor \\
\hline 0 - Off-topic & $\begin{array}{l}\text { There is written content, but not relevant to the subject under } \\
\text { discussion. }\end{array}$ \\
\hline 1 - Prestructural & $\begin{array}{l}\text { No evidence any kind of understanding but irrelevant information is } \\
\text { used, the topic is misunderstood, or arguments are unorganised. }\end{array}$ \\
\hline 2 - Unistructural & $\begin{array}{l}\text { A single aspect is explored and obvious inferences drawn. Evidence of } \\
\text { recall of terms, methods and names. }\end{array}$ \\
\hline 3 - Multistructural & $\begin{array}{l}\text { Several facets are explored, but are not connected. Evidence of } \\
\text { descriptions, classifications, use of methods and structured arguments. }\end{array}$ \\
\hline 4 - Relational & $\begin{array}{l}\text { Evidence of understanding of relationships between several aspects and } \\
\text { how they may combine to create a fuller understanding. Evidence of } \\
\text { comparisons, analysis, explanations of cause and effect, evaluations and } \\
\text { theoretical considerations. }\end{array}$ \\
\hline $\begin{array}{l}5 \text { - Extended } \\
\text { abstract }\end{array}$ & $\begin{array}{l}\text { Arguments are structured from different standpoints and ideas } \\
\text { transferred in novel ways. Evidence of generalisation, hypothesis } \\
\text { formation, theorising and critiquing. }\end{array}$ \\
\hline
\end{tabular}

Source: Karaksha et al. 2014.

The model has been adopted in a variety of contexts; Shea et al. (2013) extends CoI with quantitative CA and social network analysis methods, Joksimovic et al. (2014) correlates language use with CoI dimensions, Kovanovic et al. (2014) adopt the framework in their study into learners' social capital, and Kitto et al. (2015) cite CoI in support of their 'Connected Learning Analytics' toolkit.

\section{Digital Artefacts for Learning Engagement framework}

The DiAL-e framework (Atkinson 2009) was devised to support the creation of pedagogically effective learning interventions using Web-based digital content. It adopts 10 overlapping learning design categories (Table 4) to describe engagement

Table 3. Community of Inquiry: Cognitive Presence.

\begin{tabular}{ll}
\hline CoI score & \multicolumn{1}{c}{ Descriptor } \\
\hline $\begin{array}{l}\text { 0-Off-topic } \\
\text { 1 - Triggering } \\
\text { event }\end{array}$ & $\begin{array}{l}\text { There is written content, but not relevant to the subject under discussion. } \\
\text { A contribution that exhibits a sense of puzzlement deriving from an issue, } \\
\text { dilemma or problem. Includes contributions that present background } \\
\text { information, ask questions or move the discussion in a new direction. } \\
\text { A comment that is seeking a fuller explanation of relevant information. } \\
\text { This can include brainstorming, questioning and exchanging information. } \\
\text { Contributions are unstructured and may include: unsubstantiated } \\
\text { contradictions of previous contributions, different unsupported ideas or } \\
\text { themes, and personal stories. }\end{array}$ \\
$\begin{array}{l}\text { Previously developed ideas are connected. Contributions include: } \\
\text { references to previous messages followed by substantiated agreements or } \\
\text { disagreements; developing and justifying established themes; cautious } \\
\text { hypotheses providing tentative solutions to an issue. }\end{array}$ \\
$\begin{array}{l}\text { New ideas are applied, tested and defended with real world examples. } \\
\text { Involves methodically testing hypotheses, critiquing content in a } \\
\text { systematic manner, and expressing supported intuition and insight. }\end{array}$ \\
\hline - Resolution
\end{tabular}

Source: Garrison, Anderson, and Archer 2001. 
Table 4. Adapted DiAL-e framework.

\begin{tabular}{|c|c|}
\hline $\begin{array}{l}\text { DiAL-e } \\
\text { category }\end{array}$ & Descriptor \\
\hline Narrative & $\begin{array}{l}\text { A contribution that includes a story or narrative based on relevant themes } \\
\text { or required task. }\end{array}$ \\
\hline Author & A concrete example of applied learning. \\
\hline Empathise & A contribution that evidences understanding of other perspectives. \\
\hline Collaborate & A contribution that encourages on-topic interaction and collaboration. \\
\hline Conceptualise & $\begin{array}{l}\text { A comment that evidences reflection, explorations of 'what if' scenarios, } \\
\text { theorising, and making comparisons. }\end{array}$ \\
\hline Inquiry & $\begin{array}{l}\text { Contributions that attempt to solve a real world issue, including questions } \\
\text { and comments aimed at developing enquiry. }\end{array}$ \\
\hline Research & Indications of attempts at research as well as presentation of evidence. \\
\hline Representation & $\begin{array}{l}\text { Reflections on the presentation of course information and supporting } \\
\text { media. }\end{array}$ \\
\hline Figul & Using content as an allegory or metaphor for other purposes (e.g. parody). \\
\hline Off-t & There is written content, but not relevant to the subject under discussion. \\
\hline
\end{tabular}

Source: Atkinson 2009.

with learning activities, and is pragmatically grounded 'in terms of what the learner does, actively, cognitively, with a digital artefact' (Atkinson 2009). Case study research indicates that practitioners gain value from using the framework (Burden and Atkinson 2008), and DiAL-e has been adopted as a pedagogical model in studies that evaluate Web-based learning environments (O'Riordan, Millard, and Schulz 2015; Kobayashi 2013).

\section{Learning analytics}

The underlying assumptions of LA are based on the understanding that Web-based proxies for behaviour can be used as evidence of knowledge, competence and learning. Through the collection and analysis of interaction data (e.g. learners' search profiles and their website selections) learning analysts explore 'how students interact with information, make sense of it in their context and co-construct meaning in shared contexts' (Knight, Buckingham Shum, and Littleton 2014, p. 31). LA methods that focus on discussion forums include learner activity, sentiment analysis, and interaction between learners within forums (Ferguson 2012) which may be used to predict likely course completion.

\section{Methodology}

Comments posted on MOOC forums were manually rated by reference to the selected CA methods. Ratings for Bloom, SOLO and CoI were based on the application of values to whole comments, whereas the adapted DiAL-e model used aggregated scores derived from the number of DiAL-e category examples observed in each comment. For example, a comment coded using DiAL-e may contain a question, an indication of research activity (e.g. a hyperlink to a relevant resource), and a statement supporting a previous comment. This would result in an aggregated score of 3 - one for inquiry, one for research and one for collaboration. As with the other three methods, this score is referred to in the rest of this study as the pedagogical value (PV). The results of this coding were assessed for intra-rater reliability. Following earlier work suggesting 


\section{T. O’Riordan et al.}

the usefulness of further research into coding based on pedagogical frameworks (O'Riordan, Millard, and Schulz 2015), analysis in this study seeks to test the hypothesis that PVs for each CA method are closely correlated, and explores the implications of this to the development of the automated analysis of online learning. In order to explore possible correlations between inferred learning activity (from scores derived from CA), with typical measures of engagement, the level of positive userfeedback ('likes' per comment and comment sentiment) and language complexity (words per sentence) were also evaluated.

\section{Data collection and analysis}

An anonymised dataset derived from comment fields associated with 'The Archaeology of Portus' MOOC offered on the FutureLearn platform in June 2014 was used in this study. More than 20,000 asynchronous comments, generated by nearly 1,850 contributors (both learners and educators) occurred within the comment fields of each of the 110 learning 'steps' offered during the 6 weeks of the course.

Qualitative and quantitative content analyses were undertaken manually by the main author using four different methods, on a sample of 600 comments (the MOOC2014 corpus). Qualitative analysis comprised of assessing and coding the MOOC2014 corpus using a CA scheme developed from the CoI cognitive presence dimension (Table 3), as well as thematic analysis schemes developed from Bloom's Taxonomy (Table 1), SOLO taxonomy (Table 2) and the DiAL-e framework (Table 4). In total, each entire comment was coded four times using all methods, with a 7-day interval between the application of methods.

De Wever et al. (2006) argue that reliability is the primary test of objectivity in content studies, where establishing high replicability is important. Intra-rater reliability (IRR) tests were undertaken on 120 comments randomly selected from the MOOC2014 corpus. The results of this coding were assessed for IRR. Similar to inter-rater reliability, which measures the degree of agreement between two or more coders, IRR quantifies the level of agreement achieved with one coder assessing a sample more than once, after a period of time has elapsed. While not as robust as methods employing multiple coders, testing for IRR is viewed as an early stage in establishing replicability, provides an indication of coder stability (Rourke et al. 2001, p. 13), and is an appropriate measure for the small-scale, exploratory study reported here.

Many different indicators are used to report IRR (e.g. percent agreement, Krippendorff's alpha, and Cohen's kappa), in this case the intra-class correlations (ICC) method was adopted as it is appropriate for use with the ordinal data under analysis (Hallgren 2012). ICC was calculated using SPSS software and produced results of between 0.9 and 0.951 (Table 5), suggesting that that IRR is substantial for this sample (Landis and Koch 1977).

Table 5. Intra-rater reliability values.

Instrument

Instrument

Community of inquiry

SOLO

Bloom

DiAL-e
Interclass correlation coefficient 


\section{Procedure and analysis}

Quantitative analysis comprised a number of coding activities leading to statistical analysis. Comment data was manually coded and appropriate software was used to automate those parts of the procedure that required consistent and repeatable approaches to data search and numerical calculation.

\section{1: Data consolidation}

In an effort to find typical comment streams, six steps were selected based on their closeness to average word and comment count, and where less than $5 \%$ of comments were made by the most frequently posting contributor. A further six steps were selected: three with the highest number of comments and highest word count and three with the lowest number of comments and lowest word count.

\section{2: Count and categorise pedagogical activity}

The first 50 comments from each of these 12 steps were then coded, amounting to 600 out of the total 20,253 comments - a 3\% sample. Coding for Bloom, SOLO and CoI was based on the application of values to whole comments, whereas the adapted DiAL-e model used aggregated scores derived from the number of DiAL-e category examples observed in each comment. For example, a comment coded using DiAL-e may contain a question, an indication of research activity (e.g. a hyperlink to a relevant resource), and a statement supporting a previous comment. This would result in an aggregated PV of 3 - one for inquiry, one for research and one for collaboration.

\section{3: Collect and analyse typical learning measures}

The number of 'likes' per comment were counted, and words per sentence and sentiment data for each comment (calculated using LIWC2007 software) were aligned with each comment and analysed using SPSS predictive analytics software.

\section{4: Correlate PV for each instrument}

The PVs for each CA method were analysed using SPSS predictive analytics software.

\section{Results}

SPSS software was used to conduct statistical analysis across the comments. Normal distribution frequencies for all CA variables were produced, and scatter plots with fitted lines were generated to identify the existence and intensity of simple linear regression.

Hypothesis 1: PVs for each CA method are closely correlated.

Positive linear associations were made between all CA methods and each other (Table 6), all of which were highly correlated. The variables with the strongest statistically significant correlation across all three dimensions were the methods based on Bloom and SOLO taxonomies (Figure 1), but correlation with scores based on the CoI model was also high (Figure 2). 
Table 6. Content analysis methods correlations.

\begin{tabular}{lllll}
\hline Correlations & CoI & SOLO & Bloom & DiAL-e \\
\hline CoI & & $R=0.811^{* * *}$ & $R=0.83^{* * *}$ & $R=0.673^{* * *}$ \\
SOLO & $R=0.811^{* * *}$ & & $R=0.868^{* * *}$ & $R=0.693^{* * *}$ \\
Bloom & $R=0.83^{* * *}$ & $R=0.868^{* * *}$ & & $R=0.711^{* * *}$ \\
DiAL-e & $R=0.673^{* * *}$ & $R=0.693^{* * *}$ & $R=0.711^{* * *}$ & \\
\hline
\end{tabular}

$* * * p<0.001$.

Hypothesis 2: PVs for each CA method are correlated with typical interaction measures (sentiment, words per sentence, likes).

All comparisons produced graphs that indicated approximate linear relationship between the four PV dependent variables and three explanatory variables (Figures 3-5). There was a low positive correlation between all CA methods and words per sentence, a low negative correlation between all CA methods and positive sentiment, and no statistically significant relationship between the methods and 'likes' (Table 7).

Analysis shows that PV is not related to the number of 'likes' awarded to comments by users, which may indicate that within this learning environment, issues other than those strictly related to learning attention received positive feedback. However, there were statistically significant correlations between language complexity and sentiment with PV scores. Language complexity has been associated with critical thinking (Carroll 2007), and the positive association between longer sentences and higher PV scores suggest that learners' in the context of the 'steps' analysed in this MOOC, tended to use longer sentences when engaged in in-depth learning. The negative association of positive sentiment with higher PV scores indicate that learners may employ a more formal approach to writing comments that indicate critical thinking, than when writing at a more surface level.

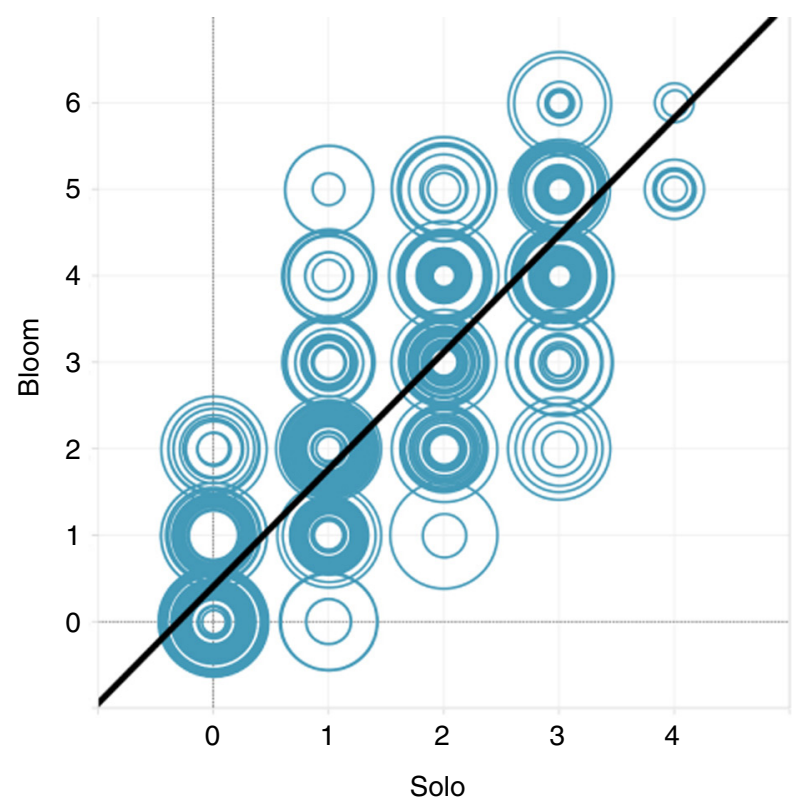

Figure 1. Correlation between Bloom and SOLO.

(Note: The size of each circle in this and following figures is related to the numbering system used to identify each comment, so that higher identification numbers result in circles with larger the diameters. Thicker circles indicate concentration of comments around specific coding decisions.) 


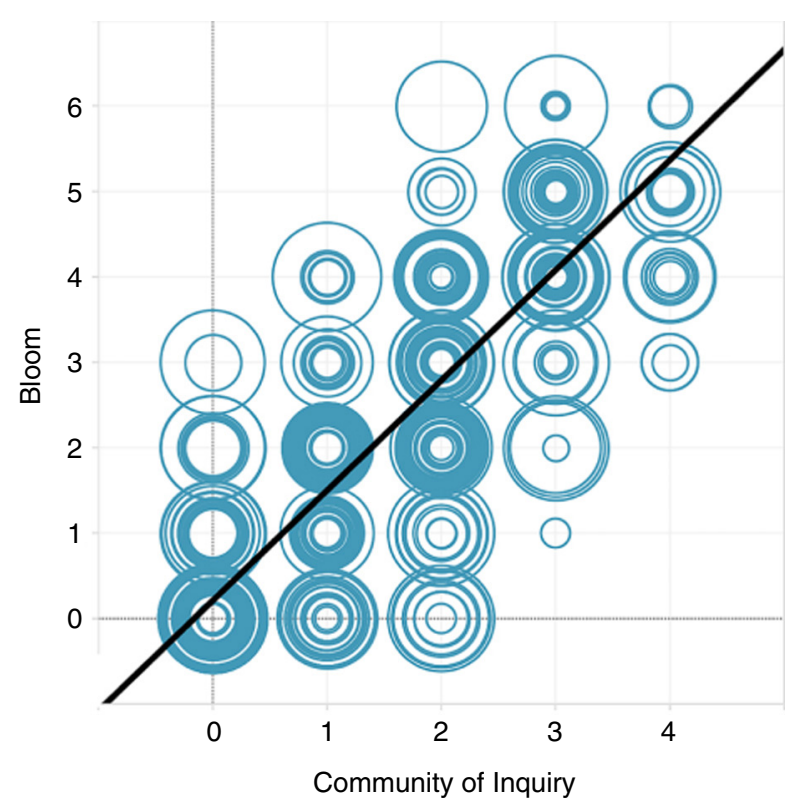

Figure 2. Correlation between Bloom and CoI.

\section{Discussion}

Improved discoverability, enhanced personalisation of learning and timely feedback are useful to learners, but only when the outcome is meaningful and adds real value to the acquisition of knowledge. This study has established that attention to learning has taken place within comments associated with learning objects. Simple measurements of this attention have been made (pedagogical value) using four different CA

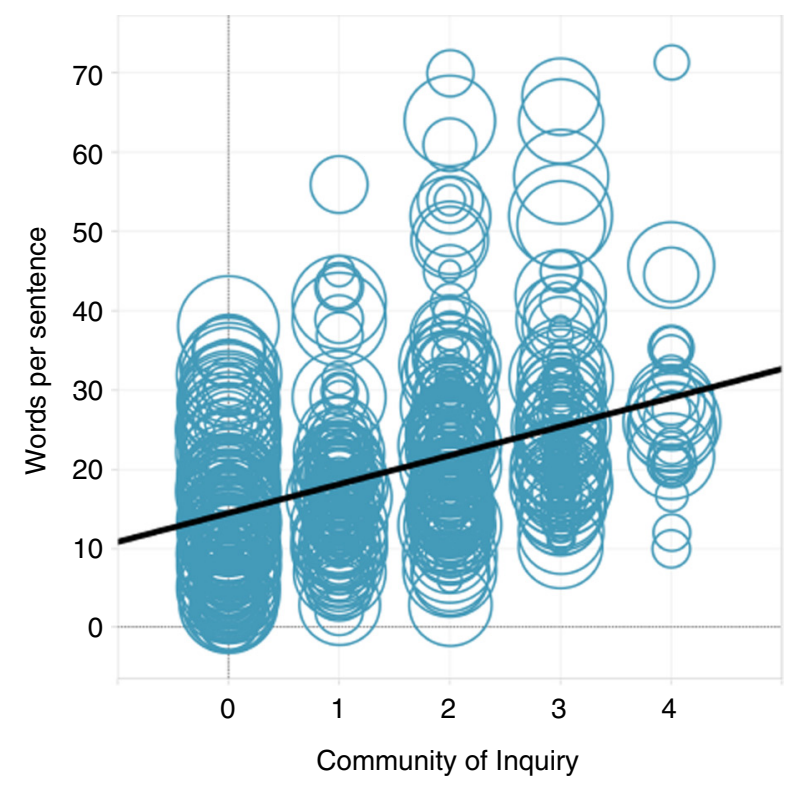

Figure 3. Correlation between CoI and WPS. 


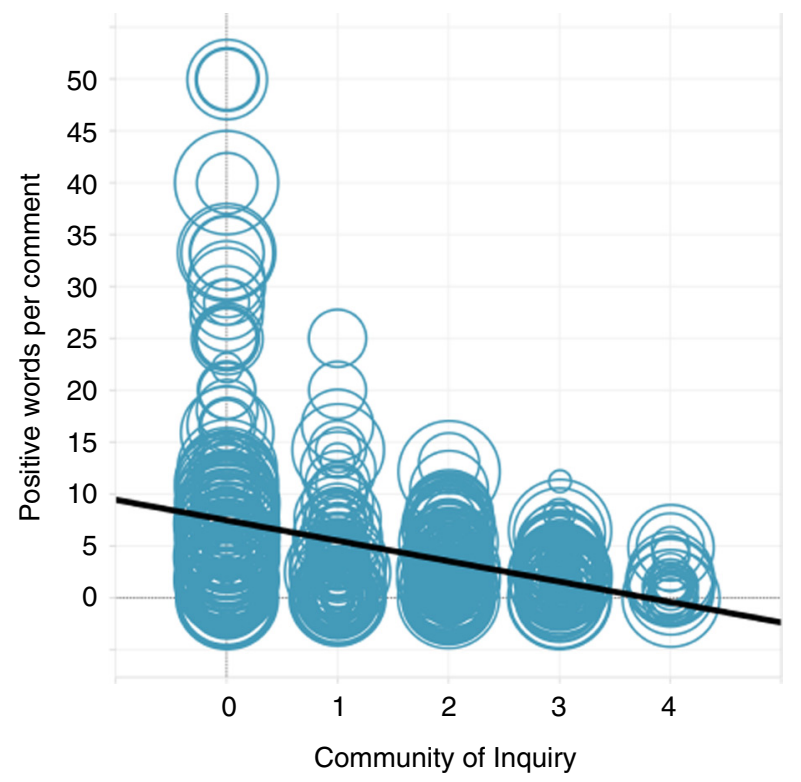

Figure 4. Correlation between $\mathrm{CoI}$ and positive words per comment.

methods, which are distinct from measuring simple 'likes' and automated analysis of language complexity.

With regard to social media 'likes', this study accords with Kelly (2012) who argues that these measures suggest a variety of ambiguous meanings, and Ringelhan, Wollersheim, and Welpe (2015) who suggest that Facebook 'likes' are not reliable predictors of traditional academic impact measures.

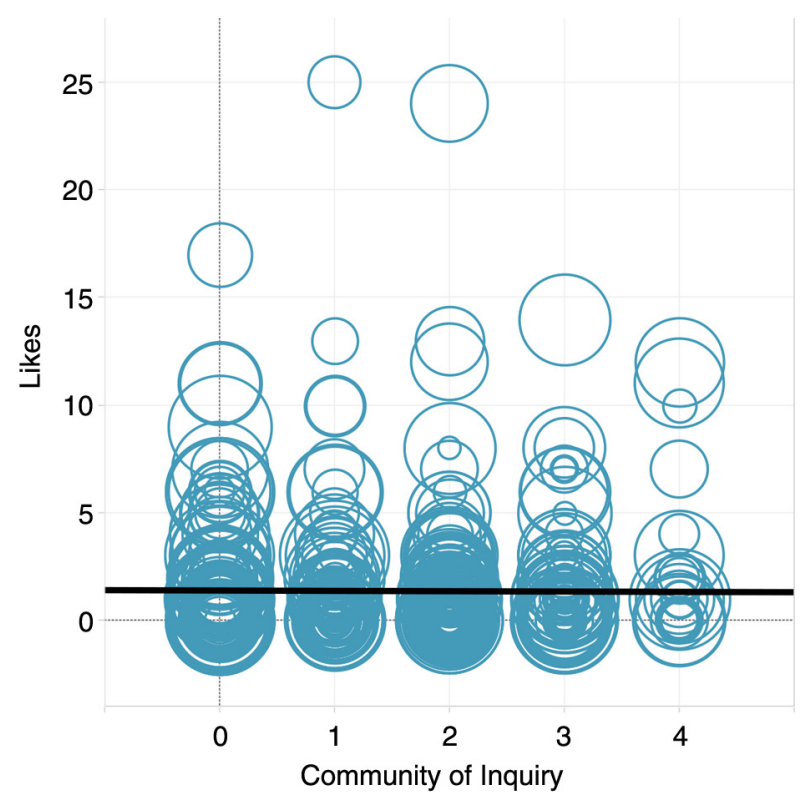

Figure 5. Correlation between $\mathrm{CoI}$ and Likes. 
Table 7. Content analysis methods correlations with typical measures.

\begin{tabular}{|c|c|c|c|}
\hline Correlations & WPS & Positive words & Likes \\
\hline $\mathrm{CoI}$ & $R=0.38 * * *$ & $R=-0.32 * * *$ & $\begin{aligned} R & =0.0 \\
p & =0.996\end{aligned}$ \\
\hline SOLO & $R=0.325^{* * *}$ & $R=-0.288^{* * *}$ & $\begin{aligned} R & =0.02 \\
p & =0.623\end{aligned}$ \\
\hline Bloom & $R=0.358^{* * *}$ & $R=-0.289^{* * *}$ & $\begin{aligned} R & =0.028 \\
p & =0.494\end{aligned}$ \\
\hline DiAL-e & $R=0.217 * * *$ & $R=-0.182^{* * *}$ & $\begin{array}{l}R=0.024 \\
p=0.559\end{array}$ \\
\hline
\end{tabular}

${ }^{* * *} p<0.001$.

Results indicate clear and statistically significant correlations between the four CA methods. It is perhaps unsurprising that the instruments derived from taxonomies designed to describe cumulative levels of understanding (Bloom and SOLO) should show the closest correlations. However, methods developed to explain the development of reflective discussion (CoI) and measure engagement in pedagogical activities (DiAL-e) are also closely associated; with each other and the other two instruments. If these instruments are measuring different things, why are they closely aligned?

There are three possible explanations for this. Firstly, they may be measuring very similar behaviours related to the depth and intensity with which people write about what they are thinking. If we agree that there is an approximate connection between complexity of writing and depth of understanding, it makes sense that someone who has applied greater attention to their learning, and wishes to share this with others, will use more elaborate arguments ('Create' in Bloom, or 'Relational' in SOLO), or attempt to sum up theirs and others ideas ('Resolution' in CoI), or demonstrate that they are engaging in a variety of activities (DiAL-e); all of which appear similar to all CA methods, and suggests that comments evidencing these types of focus will tend to be ranked in a similar manner.

The practice of coding comments revealed styles of writing that are typical of this environment but which are not accounted for in all four CA instruments. Because of the succinct nature of many comments in the sample, these are particularly evident at the lower end of the CoI, SOLO and Bloom scales. While the 'Triggering' and 'Exploration' dimensions of CoI explicitly facilitate coding for questions and some of the social dynamics characteristic of CMC (aspects which are also classifiable using the 'Inquiry' and 'Collaborate' dimensions of DiAL-e), neither SOLO nor Bloom explicitly account for these features.

SOLO and Bloom have their origins in efforts to assess the quality of student work and evaluate the success or otherwise of instructional design in achieving educational goals in formal settings. Within the context of our study this focus tends to favour the evaluation of lengthy and complete texts (e.g. essays and 'extended abstracts'). Whereas CoI, and the adaption of DiAL-e used in this study, are specifically designed to measure and comprehend the characteristics and value of critical discourse in online discussions, which affords their application to the ephemeral, fragmented styles characteristic of this environment (Herring 2012). These differences in focus inevitably lead to some instruments identifying some activities better than others, for example in the MOOC2014 corpus, examples of all dimensions in all instruments were identified 


\section{T. O’Riordan et al.}

with the exception of 'Figurative' in DiAL-e and 'Extended Abstract' in SOLO. While it should be recognised that cognition is a complex phenomenon that is not fully understood, and the simple metrics used in this study cannot explain the richness of human behaviour in this setting, Shea et al. (2011) suggest combining different CA methods as a method to achieve greater accuracy.

Finally, although IRR tests demonstrated high levels of accuracy, Garrison, Anderson, and Archer (2001) suggest that coding processes are unavoidably flawed, because of the highly subjective nature of the activity. Since one judge was involved, and coding decisions tend to reflect subjective understandings of what constitutes effective learning, there is a strong likelihood of bias entering the process. In addition, as the selected sample is biased, this may have adversely affected results for some methods. For example, while two of the steps analysed had little more than 50 comments, others contained many hundreds of comments. By coding only the first 50 of each step, the opportunity to find comments aimed at resolving discussions was reduced, which may have affected results for the CoI method more than others.

\section{Conclusions}

The aims of this study were to compare relevant and established CA methods with each other, and with typical interaction methods, with the aim of formulating recommendations on the use of these methods in future studies. Results suggest that while the CA instruments are designed to evaluate different aspects of online discussions, they are closely aligned with each other in terms evidencing very similar behaviours related to the depth and intensity of cognition. The implications of this finding have importance for instructors and learners.

Nearly 25 years ago Henri (1992) identified CA as a vital tool for educators to understand and improve learning interactions within CSCL - an issue as important now as it was then. However, despite progress in codifying CA methods, the process of coding by hand cannot successfully manage the increasing volume of data generated by online courses (Chen, Vorvoreanu, and Madhavan 2014) and requires the development of appropriate automatic methods. In this study, we have identified strong correlations between all CA methods, and between these methods and learners' use of language, which suggests potential for developing real-time, automated feedback systems that can identify areas in need of intervention.

While this small-scale study contributes to understanding the limits of the use of 'likes' as indicators of on-topic engagement, and establishes links between learners' language use and their depth of learning, we believe that further CA of different datasets from many other courses with contributions made by different participants, covering diverse subjects, and analysed by multiple raters is required to establish widely applicable methods.

Looking further, our future work will endeavour to build on this broader CA and the linear regressions presented in this paper, and engage with machine learning (ML) techniques to develop real-time, automated feedback systems. The potential of ML's computational processes is in the combination of multiple metrics (e.g. CA scores, word counts and sentiment) in order to predict PVs and provide meaningful feedback. Our expectation is that ML-based tools may be employed to support self-directed learning, enable educators to identify those learners who are experiencing difficulties as well as those who are doing well, and help learning technologists design more effective CSCL environments. In order for educators to successfully manage the high volume of diverse 
learning interactions inherent in massive courses, the development of this type of software is becoming increasingly important.

\section{Conflict of interest and funding}

This work was funded by the RCUK Digital Economy Programme. The Digital Economy Theme is a Research Councils UK cross council initiative led by EPSRC and contributed to by AHRC, ESRC, and MRC. This work was supported by the EPSRC, grant number EP/G036926/1.

\section{References}

Atkinson, S. (2009) What is the DiAL-e framework? [online] Available at: http://dial-e.net/ what-is-the-dial-e/

Biggs, J. B. \& Collis, K. F. (1982) Evaluating the Quality of Learning: Structure of the Observed Learning Outcome Taxonomy, Academic Press, New York, NY.

Bloom, B. S., Engelhart, M. D., Furst, E. J., Hill, W. H. \& Krathwohl, D. R. (1956) Taxonomy of Educational Objectives. The Classification of Educational Goals. Handbook 1, ed. B. S. Bloom, McKay, New York, NY.

Burden, K. \& Atkinson, S. (2008) 'Beyond content: developing transferable learning designs with digital video archives', Proceedings of World Conference on Educational Multimedia, Hypermedia and Telecommunications, Vienna, Austria, pp. 4041-4050.

Campbell, R. J. (2015) 'Constructing learning environments using the SOLO taxonomy', Scholarship of Learning and Teaching (SoTL) Commons Conference, Georgia Southern University, Savannah, GA. Available at: http://digitalcommons.georgiasouthern.edu/sotlcommons/SoTL/2015/75

Carroll, D. W. (2007) 'Patterns of student writing in a critical thinking course: a quantitative analysis', Assessing Writing, vol. 12, no. 3, pp. 213-227.

Chan, C. C., Tsui, M. S., Chan, M. Y. C. \& Hong, J. H. (2002) 'Applying the structure of the observed learning outcomes (SOLO) taxonomy on student's learning outcomes: an empirical study', Assessment \& Evaluation in Higher Education, vol. 27, no. 6, pp. 511-527.

Chen, X., Vorvoreanu, M. \& Madhavan, K. (2014) 'Mining social media data for understanding students' learning experiences', IEEE Transactions on Learning Technologies, vol. 7, no. 3, pp. $246-259$.

Cooper, M. M. \& Selfe, C. L. (1990) 'Computer authority, persuasive learning: internally', College English, vol. 52, no. 8, pp. 847-869.

De Wever, B., et al., (2006) 'Content analysis schemes to analyze transcripts of online asynchronous discussion groups: a review', Computers and Education, vol. 46, pp. 6-28.

Dringus, L. (2012) 'Learning analytics considered harmful', Journal of Asynchronous Learning Networks, vol. 16, no. 3, pp. 87-100.

Ferguson, R. (2012) 'Learning analytics: drivers, developments and challenges', International Journal of Technology Enhanced Learning, vol. 4, no. 5/6, pp. 304-317.

Ferguson, R. \& Sharples, M. (2014) 'Innovative pedagogy at massive scale: teaching and learning in MOOCs', in Open Learning and Teaching in Educational Communities, eds. S. I. de Freitas, T. Ley \& P. J. Muñoz-Merino, Springer International Publishing, Cham, Switzerland, pp. 98-111.

Garrison, D. R., Anderson, T. \& Archer, W. (2001) 'Critical thinking, cognitive presence, and computer conferencing in distance education', American Journal of Distance Education, vol. 15 , no. 1 , pp. $7-23$.

Garrison, D. R., Anderson, T. \& Archer, W. (2010) 'The first decade of the community of inquiry framework: a retrospective', Internet and Higher Education, vol. 13, no. 1-2, pp. 5-9.

Gerbic, P. \& Stacey, E. (2005) 'A purposive approach to content analysis: designing analytical frameworks', Internet and Higher Education, vol. 8, pp. 45-59.

Gibson, A., Kitto, K. \& Willis, J. (2014) 'A cognitive processing framework for learning analytics', 4th International Conference on Learning Analytics and Knowledge (LAK 14), Indianapolis, IN, pp. 1-5. 


\section{T. O’Riordan et al.}

Ginat, D. \& Menashe, E. (2015) 'SOLO taxonomy for assessing novices' algorithmic design', SIGCSE '15 Proceedings of the 46th ACM Technical Symposium on Computer Science Education, New York, NY, pp. 452-457.

Hallgren, K. A. (2012) 'Computing inter-rater reliability for observational data: an overview and tutorial', Tutorials in Quantitative Methods for Psychology, vol. 8, no. 1, pp. 23-34.

Henri, F. (1992) 'Computer conferencing and content analysis', in Collaborative Learning through Computer Conferencing, ed. A. R. Kaye, The Najadan Papers, Springer, Berlin, pp. 117-136.

Herring, S. C. (2012) 'Grammar and electronic communication', in The Encyclopedia of Applied Linguistics, ed. C. Chapelle, Wiley-Blackwell, Hoboken, NJ, pp. 1-9.

Hiltz, S. R. (1981) The Impact of a Computerized Conferencing System on Scientific Research Communities, Final Report to the National Science Foundation, Research Report No. 15. Computerized Conferencing and Communications Center, New Jersey Institute of Technology, Newark, New Jersey.

Joksimovic, S., et al., (2014) 'Psychological characteristics in cognitive presence of communities of inquiry: a linguistic analysis of online discussions', The Internet and Higher Education, vol. 22, pp. 1-10.

Karaksha, A., Grant, G., Nirthanan, S. N., Davey, A. K. \& Anoopkumar-Dukie, S. (2014) 'A comparative study to evaluate the educational impact of e-Learning tools on griffith university pharmacy students' level of understanding using bloom's and SOLO taxonomies', Education Research International, vol. 2014, pp. 1-11.

Kelly, B. (2012) 'What's next, as Facebook use in UK universities continues to grow?', Impact of Social Sciences, LSE Blog, [online] Available at: http://blogs.lse.ac.uk/impactofsocial sciences/2012/06/19/facebook-universities-continue-grow/

Kember, D. (1999) 'Determining the level of reflective thinking from students' written journals using a coding scheme based on the work of Mezirow', International Journal of Lifelong Education, vol. 18, pp. 18-30.

Khawaja, M. A., et al., (2009) 'Cognitive load measurement from user's linguistic speech features for adaptive interaction design', Lecture Notes in Computer Science, vol. 5726, no. Part 1, pp. 485-489.

Kitto, K., et al., (2015) 'Learning analytics beyond the LMS: the connected learning analytics toolkit', Proceedings of the Fifth International Conference on Learning Analytics and Knowledge - LAK'15, ACM, Poughkeepsie, NY, pp. 11-15.

Knight, S., Buckingham Shum, S. \& Littleton, K. (2014) 'Epistemology, assessment, pedagogy: where learning meets analytics in the middle space', Journal of Learning Analytics, vol. 1, no. 2 , pp. $23-47$.

Kobayashi, M. (2013) 'Using web 2.0 in online learning: what students said about voice thread', EdMedia: World Conference on Educational Media and Technology, Victoria, Canada, pp. 234-235.

Kosinski, M., Stillwell, D. \& Graepel, T. (2013) 'Private traits and attributes are predictable from digital records of human behavior', Proceedings of the National Academy of Sciences, vol. 110 , no. 15 , pp. $5802-5805$.

Kovanovic, V., et al., (2014) 'What is the source of social capital? The association between social network position and social presence in communities of inquiry', Proceeding of Workshop on Graph-based Educational Data Mining at Educational Data Mining Conference (G-EDM 2014), London, pp. 1-8.

Krathwohl, D. R. (2002) 'A revision of Bloom's Taxonomy: an overview', Theory into Practice, vol. 41, no. 4, pp. 212-218.

Landis, J. R. \& Koch, G. G. (1977) 'The measurement of observer agreement for categorical data', Biometrics, vol. 33, no. 1, pp. 159-174.

Leshed, G., et al., (2007) 'Feedback for guiding reflection on teamwork practices', Proceedings of the 2007 International ACM Conference on Supporting Group Work - GROUP '07, ACM, Sanibel Island, FL, pp. 217-220.

McLaughlin, G. H. (1974) 'Temptations of the flesch', Instructional Science, vol. 2, pp. 367-383.

Mezirow, J. (1991) 'A critical theory of adult learning and education', in Experience and Learning: Reflection at Work, eds. D. Boud \& D. Walker, Deakin University, Geelong, pp. $61-82$. 
Naccarato, J. L. \& Neuendorf, K. A. (1998) 'Content analysis as a predictive methodology: recall, readership, and evaluations of business-to-business print advertising', Journal of Advertising Research, vol. 38, no. 3, pp. 19-33.

O'Riordan, T., Millard, D. E. \& Schulz, J. (2015) 'Can you tell if they're learning?: using a pedagogical framework to measure pedagogical activity', ICALT 2015: 15th IEEE International Conference on Advanced Learning Technologies, IEEE, Hualien, TW, pp. 265-267.

Ramesh, A., Goldwasser, D., Huang, B., Daum, H. \& Getoor, L. (2013) 'Modeling learner engagement in MOOCs using probabilistic soft logic', Neural Information Processing Systems Workshop Data Driven Education, Lake Tahoe, Nevada., pp. 1-7.

Ringelhan, S., Wollersheim, J. \& Welpe, I. M. (2015) 'I like, I cite? Do Facebook likes predict the impact of scientific work? PLoS One, vol. 10, no. 8, pp. 1-21.

Robinson, R. L., Navea, R. \& Ickes, W. (2013) 'Predicting final course performance from students' written self-introductions: a LIWC analysis', Journal of Language and Social Psychology, vol. 32, no. 4, pp. 469-479.

Rourke, L., et al., (2001) 'Methodological issues in the content analysis of computer conference transcripts', International Journal of Artificial Intelligence in Education, vol. 12, pp. 8-22.

Shea, P., et al., (2011) 'The Community of Inquiry framework meets the SOLO taxonomy: a process-product model of online learning', Educational Media International, vol. 48, no. 2, pp. 101-113.

Shea, P., et al., (2013) 'Online learner self-regulation: learning presence viewed through quantitative content- and social network analysis', International Review of Research in Open and Distance Learning, vol. 14, pp. 427-461.

Walther, J. B. (2007) 'Selective self-presentation in computer-mediated communication: hyperpersonal dimensions of technology, language, and cognition', Computers in Human Behavior, vol. 23, no. 5, pp. 2538-2557.

Weltzer-Ward, L. (2011) 'Content analysis coding schemes for online asynchronous discussion', Campus-Wide Information Systems, vol. 28, pp. 56-74.

Wen, M., Yang, D. \& Rosé, C., (2014) 'Sentiment analysis in MOOC discussion forums: what does it tell us?', Proceedings of 7th International Conference on Educational Data Mining (EDM2014), London, UK, pp. 130-137.

Yang, D., et al., (2011) 'The development of a content analysis model for assessing students' cognitive learning in asynchronous online discussions', Educational Technology Research and Development, vol. 59, pp. 43-70. 